Provided for non-commercial research and education use. Not for reproduction, distribution or commercial use.

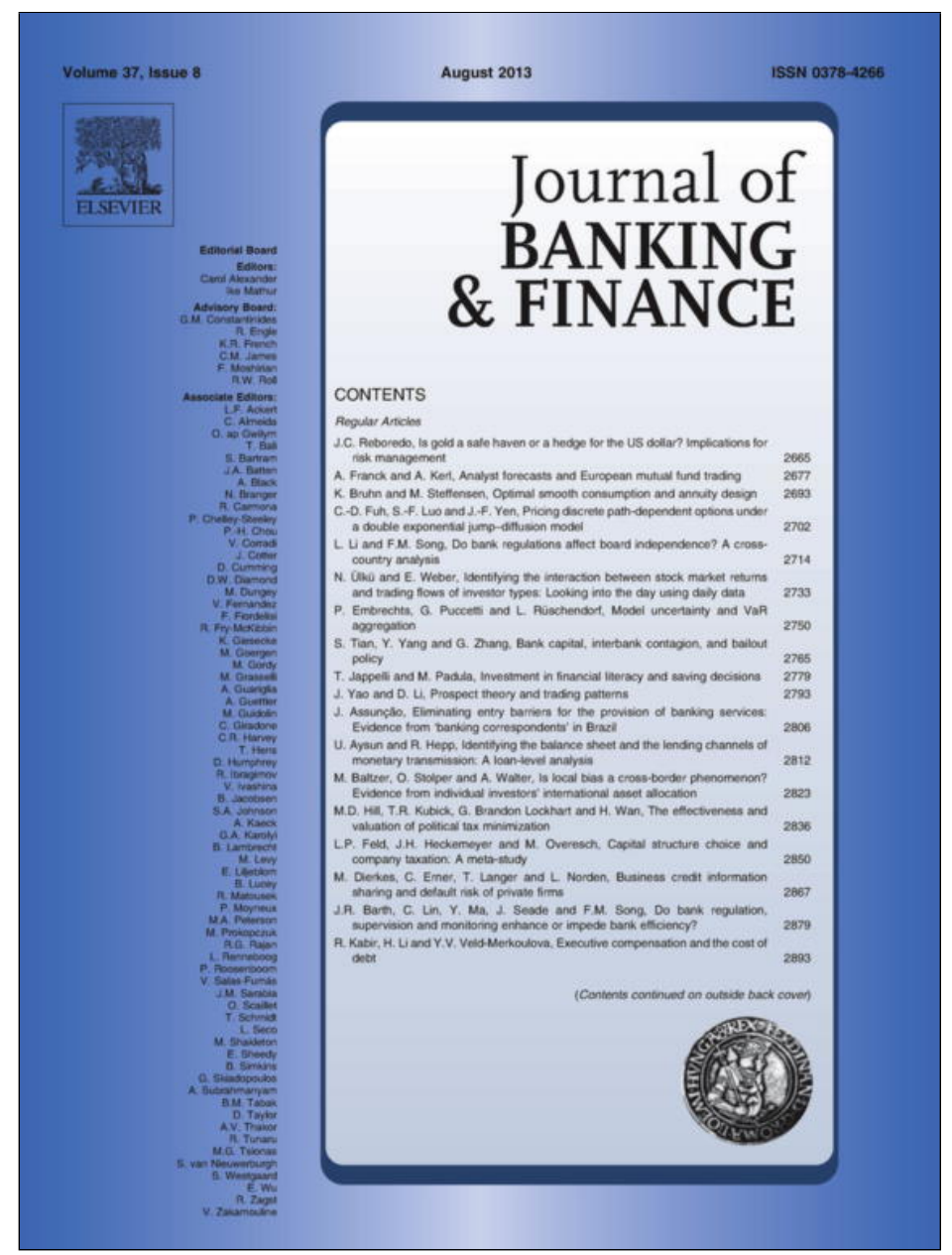

This article appeared in a journal published by Elsevier. The attached copy is furnished to the author for internal non-commercial research and education use, including for instruction at the authors institution and sharing with colleagues.

Other uses, including reproduction and distribution, or selling or licensing copies, or posting to personal, institutional or third party websites are prohibited.

In most cases authors are permitted to post their version of the article (e.g. in Word or Tex form) to their personal website or institutional repository. Authors requiring further information regarding Elsevier's archiving and manuscript policies are encouraged to visit:

http://www.elsevier.com/authorsrights 


\title{
Capital controls in Brazil - Stemming a tide with a signal?
}

\author{
Yothin Jinjarak $^{\mathrm{a}, \mathrm{f}}$, Ilan Noy ${ }^{\mathrm{b}, \mathrm{c}}$, Huanhuan Zheng ${ }^{\mathrm{d}, \mathrm{e}, *}$ \\ ${ }^{a}$ DeFiMS SOAS, University of London, United Kingdom \\ ${ }^{\mathrm{b}}$ University of Hawaii, United States \\ ${ }^{\mathrm{c}}$ Victoria Business School, Victoria University of Wellington, New Zealand \\ ${ }^{\mathrm{d}}$ The University of York, United Kingdom \\ e Institute of Global Economics and Finance, The Chinese University of Hong Kong, Hong Kong \\ ${ }^{\mathrm{f}}$ ADB Institute, Tokyo, Japan
}

\section{A R T I C L E I N F O}

\section{Article history:}

Received 18 November 2012

Accepted 14 April 2013

Available online 1 May 2013

\section{JEL classification:}

F32

G23

E60

Keywords:

Capital control

Brazil

Global financial crisis

Mutual fund flows

Exchange rate

\begin{abstract}
A B S T R A C T
Controls on capital inflows have been experiencing a renaissance since 2008, with several prominent emerging markets implementing them in recent years. We focus on Brazil, which instituted five changes in its capital account regime in 2008-2011. Using the synthetic control method, we construct counterfactuals (i.e., Brazil with no policy change) for each of these changes. We find no evidence that any tightening of controls was effective in reducing the magnitudes of capital inflows, but we observe some modest and short-lived success in preventing further declines in inflows when the capital controls were relaxed. We hypothesize that price-based capital controls' only perceptible effect is to be found in the content of the signal they broadcast regarding the government's larger intentions and sensibilities. In the case of Brazil, its left-of-center government's willingness to remove controls was perceived as a noteworthy indication that the government was not as hostile to the international financial markets as many expected it to be.
\end{abstract}

(C) 2013 Elsevier B.V. All rights reserved.
"What was just a trickle of controls before the current crisis is now a flood."

(Financial Times, October 25, 2010).

"That option may not be available to ... Brazil, where inflation remains a problem. In their case, limited capital controls may be a sensible short-term defence against destabilizing inflows of hot money."

(The Economist, February 16, 2013).

\section{Introduction}

Controls on capital inflows have been experiencing a period akin to a renaissance since the beginning of the global financial

\footnotetext{
* Corresponding author. Address: 13/F, Cheung Yu Tung Building, 12 Chak Cheung Street, Shatin, NT, Hong Kong. Tel.: +852 3943 1665; fax: +852 26035230

E-mail addresses: yj5@soas.ac.uk (Y. Jinjarak), noy@hawaii.edu (I. Noy), arwenzh@gmail.com (H. Zheng).
}

crisis in 2008. This renaissance has manifested itself most importantly in prominent cases of new controls being put in place; most notably were Thailand, Korea, Peru, Indonesia, Brazil, and Iceland. ${ }^{1}$ In conjunction with this re-emergence of controls as an actual policy, the theoretical literature has also shifted with now several contributions that explain the possible advantages of short-term controls using theoretical models. ${ }^{2}$

Maybe the most pronounced shift has occurred at the International Monetary Fund (IMF). The IMF has advocated the removal of all controls on outflows and inflows throughout the 1990s. ${ }^{3}$ The Asian Crisis of 1997-1998, however, initiated a very slow process of conversion within the IMF that culminated recently with its decision

\footnotetext{
${ }^{1}$ The most basic distinction is between controls on outflows and inflows. The economics literature consistently finds controls on outflows as inefficient and harmful. Binici et al. (2010) provide a recent empirical attempt to differentiate between the impact of controls on outflows and inflows.

2 Jeanne (2012a), provides a selective summary of this new theoretical literature; a more recent examination that looks at the impact of capital account policies on the real exchange rate is available in Jeanne (2012b).

3 The IMF's campaign to liberalize capital flows culminated in an attempt to insert this aim into its charter - see Joyce and Noy (2008) for details and empirical evidence.
} 
to explicitly and openly support the imposition of controls on capital inflows. ${ }^{4}$ The basic premise of this new IMF stance on capital controls is that these should be imposed when countries are facing a capital inflow surge and after other policy alternatives have been exhausted.

Here, we are interested in examining whether capital controls on inflows, imposed at the time of an inflow surge, are effective? And if they are, what are their effects? We attempt to answer these questions using the Brazilian experience of 2008-2011 in imposing new (price-based) controls as the Global Financial Crisis (GFC) enfolded. A prevailing view today is that controls should only be imposed in these kinds of crisis circumstances, rather than as 'business-as-usual' policies; and this position justifies our choice to focus on Brazil's policy during the evolution of the GFC. ${ }^{5}$

There are broadly five possible impacts of capital controls on inflows: (1) reduce the volume of capital inflows; (2) change the composition of inflows (in accordance with the specific controls imposed); (3) impact the real exchange rate (preventing an appreciation); (4) enable a more independent pursuit of monetary policy (as it relaxes the international trilemma's constraints); and (5) increase/decrease financial stability. ${ }^{6}$ We are unable to directly deal with the second impact (composition of flows) given our data limitations and choose not to examine the impact on financial stability since this is a longer-term impact, and our focus here is on the short term ( 3 months). We thus focus on the volume of capital inflows, on the exchange rate, and on domestic monetary policy (the interest rate).

There are two recent survey papers on capital controls (Magud et al., 2011; Ostry et al., 2012). Both find that the empirical literature on the impacts of capital controls is inconclusive, with some observed effects on the composition of flows, but very little effect on volumes of flows (and even less agreement on the impact of controls on the exchange rate and policy/interest rates). ${ }^{7}$

As Magud et al. (2011) point out, this evaluation of capital-controls literature suffers from several apples-to-oranges problems. Most relevant to our work are two problems: First, the literature mostly ignores the heterogeneity of capital controls imposed across countries and over time, and uses cross-country comparisons that utilize control indices that hide these distinctions (the ones developed by Miniane (2004), Chinn and Ito (2006), and Schindler (2009), are frequently used). Second, the case-studies literature focuses almost exclusively on the two poster-children of capital controls, Malaysia (outflows) and Chile (inflows). ${ }^{8}$

Another distinction that appears important is the distinction between short- and long-term impacts of capital account policies. Long-term impacts, while potentially more important, are generally more difficult to identify precisely, and this has certainly been the case in this literature. Many of the papers that do 'manage' to identify some precise impact of controls, do so only in the shortterm, and fail to find any longer-term effects. The IMF, in its support for re-considering the use of capital control as a policy, argues that their use should be temporary, and their aim is precisely to

\footnotetext{
${ }^{4}$ The most recent summary of this new IMF view is available in IMF (2012). Fig. 1 in Ostry et al. (2011) provides a parsimonious summary of the caveats and preconditions that, according to the IMF, should accompany the imposition of controls.

${ }^{5}$ Klein (2012) employs a related distinction between controls as gates (temporary and specific measures) and controls as walls (aiming to block most or all cross-border capital transactions regularly).

6 The evidence on financial stability in general, and in particular about the impact of controls on the likelihood of financial crises is quite mixed (see, for example, Glick et al., 2006).

7 We do not provide a significant review of this large literature since these two recent surveys are available. An earlier survey of this literature is Edwards (1999).

${ }^{8}$ Malaysia famously imposed temporary controls on capital outflows in the aftermath of the Asian Crisis of 1997-1998, and this act generated a heated debate on the topic. Chile imposed a set of taxes on short-term flows in the 1990s that were fairly widely perceived as successful in lengthening the maturity of flows.
}

have a short-term effect on the volume of capital inflows. We thus focus here exclusively on the question of the short-term, and ignore long-term effects, which are probably unidentifiable with our methodology, even if they exist at all.

We focus on a set of controls imposed (and relaxed) by Brazil in the last few years, in an attempt to control the amount of capital flowing into the country. By focusing on Brazil during the Global Financial Crisis we directly examine the IMF's support for imposition of controls in the face of capital inflow surges in a country that has financial markets that are largely open to capital flows.

We use micro-level data on capital flows from mutual funds investing internationally, and a new methodology to estimate the counter-factual (no imposition of controls). We use a methodological innovation recently formalized in Abadie et al. (2010, henceforth ADH). The methodology is based on simulating conditions after an exogenous event (in their case, a change in the tax rate, in ours, the imposition or change in the rules governing capital inflows). The synthetic counterfactual's construction is based on the relationship to a control group. The ADH algorithm does not presume to impose any ad hoc assumptions about the likely control group, but rather derives this control group as a weighted average of observations from all the non-treated units of observations with weights estimated from pre-treatment data (in our case the nontreated units are countries that have not changed their capital account policies during our sample). The ADH procedure allows us to construct a no-policy-change counterfactual and thus measure in detail the impact of the controls themselves. It further does not require us to make many structural assumptions that would have been difficult to theoretically justify.

To be thorough, we need to find a way to examine all five possible impacts. We have weekly data on capital inflows from mutual funds and examine the evolution of these inflows in the aftermath of imposition of controls. Our data does not allow us to examine the impact of controls on other types of flows such as foreign direct investment or bank loans, but the flows we examine are relatively representative. ${ }^{9}$ In addition to examining the impact on equity flows, we also look for any impact of the controls on exchange rate. We use the same synthetic control methodology (Abadie et al., 2010) in order to develop an alternative counter-factual exchange rate without controls. Again, the ADH methodology allows us to skirt the difficulty of wedding our analysis to any one exchange-ratedetermination model; since the literature on the determination of exchange rates is both voluminous and contentious. We implement the same methodology for interest rates, but since interest rate policy changed very little during this time period in Brazil, our model is not good enough to capture accurately a synthetic control with a good fit for the ex ante data. Given that limitation, we do not present our results regarding interest rates but rather briefly describe them at the end of the next section. We do not examine financial stability since our focus is the short-term ( 3 months) rather than the longterm that is at the core of the financial stability argument.

\section{Capital controls and flows in Brazil - the data details}

\subsection{The controls}

Brazil liberalized its capital flow regimes gradually starting from the early 1990s, culminating in an almost completely open capital account by the mid-2000s, including a flexible exchange rate regime (see Goldfajn and Minella, 2005; Carvalho and Garcia, 2008, for details and Baba and Kokenyne 2011, for an evaluation of this capital account regime in the run-up to just before the global financial crisis). After a fairly brief period of no taxes on foreign

\footnotetext{
${ }^{9}$ A comparison with capital flow data from the IMF's Balance of Payments Statistics dataset is available in Appendix C.
} 
capital transactions, taxes were reintroduced in March 2008 at the rate of $1.5 \%$ on fixed-income investments. ${ }^{10}$ Investments related to equities remained exempt from taxes for a while later. ${ }^{11}$ The tax was reduced to zero in October 2008 at the peak of the global financial crisis, when the exchange rate came under depreciation pressures (as in many other big emerging markets). A $2 \%$ tax on fixed-income and equity inflows was reintroduced in October 2009 with further widening its application the next month. The tax was later increased to $6 \%$ in two stages (in October 2010); but then reduced back down to $2 \%$ in January $2011 .^{12}$

\subsection{The flows}

The weekly mutual fund flows data we use are from Emerging Portfolio Fund Research (EPFR) dataset. We calculate the weekly flows to a specific country as the aggregate flows channeled specifically to this country (from mutual funds whose focus is countryspecific). For robustness, we also calculate the broad regional flows to Latin America, which are the sum of all flows channeled to this region including flows that target a broader regional market, e.g. Latin America, and evaluate its response to Brazilian capital control. We use the weekly EPFR fund data, rather than the monthly measures both because we are interested in the weekly dynamics following policy treatment, and as we find that these weekly fund data is better correlated with the International Financial Statistics' Balance of Payments portfolio data than the EPFR monthly aggregates.

In a similar manner, we calculate the Total Net Asset under management (TNA) by summing up the TNA of all funds targeting the designated country; and obtain the mutual fund return by taking the aggregated return of all funds that specialize in the designated country.

Other than the fund-specific characteristics, we also control for the country's stock and bond market performance as well as its foreign exchange rate fluctuations. Specifically, we calculate the weekly stock market return based on the national stock market index measured in local currency. Weekly bond market return is calculated similarly. Bond indices are from JP Morgan GBI and EMBI and are measured in local currency. Weekly return on foreign exchange rate is calculated as the weekly return of the local currency against USD.

For every episode of capital control, we study 12 weeks (approximately 1 quarter) before and after the control announcement date. We include a country as a possible component of the control group if (i) there are no capital controls of any kind imposed for the given sample period; and (ii) there are no missing observations in either variables described above for the given sample period. Generally, only a few small countries drop out of the sample. The final control group sample contains 33-37 countries depending on the episode. ${ }^{13}$ The list of countries used as controls in each specification is included in Appendix D.

One of the ADH algorithm's advantages is the ability to use this synthetic control methodology to estimate unbiased coefficients with relatively few pre-event observations. In our case we use 12 weekly observations pre-treatment for the estimation (see details below); a similar number to what Abadie et al. (2010) use, and only slightly less than the number used in the first paper to employ this

\footnotetext{
10 This tax, known as the IOF (imposto sobre operações financeiras), has been used during the 1990s as well.

11 In May 2008, the tax was extended to cover "simultaneous operations" to prevent circumvention of the inflow tax (circumvention which was apparently widespread).

${ }^{12}$ Tax was also expanded to cover margin calls on derivative positions and foreign borrowing with maturities below 1 year. Our dating of these capital account policy changes relies on OECD (2011), along with news readings from Reuters and Financial Times.

${ }^{13}$ In different contexts, Abadie et al. (2012) and Cavallo et al. (forthcoming) use country-level panels (annual) with a synthetic control methodology. In the first case, to examine the impact of German re-unification, in the latter to examine the macroeconomic impact of natural catastrophes.
}

methodology (Abadie and Gardeazabal, 2003). When we examine the data for the control group of countries (those whose synthetic weights are significantly different from zero) and Brazil, we generally find similar trends in the pre-treatment data, suggesting that the shocks Brazil were experiencing were common and there is no evidence to support the argument that the conditions leading to the placing of controls were unique to Brazil. None of our control countries had any change in its capital account policy implemented in our sample periods. ${ }^{14}$

\section{Methodology}

$Y_{i t}$ is the outcome variable that is evaluated based on the controls' impact on the treated country $i$, (with $i=1$ for Brazil and $i>1$ for all other countries) and time $t$ (for time periods $t=1, \ldots, T_{0}, \ldots, T$; where $T_{0}=13$ is the time of imposition of controls or a change in the control's details) and $T=25$. In this paper, we examine three outcome variables - all three variables are potential policy aims, and all may have been affected by the imposition or relaxation of capital controls: aggregate capital flows (as measured in our mutual fund database), the exchange rate, and the interest rate.

$Y_{i t}^{I}$ is the outcome variable in the presence of the controls and $Y_{i t}^{N}$ is the outcome variable had the controls not been imposed. ${ }^{15}$ The ADH methodology requires the assumption that the event has no effect on the outcome variable before the date of impact $T_{0}$ $\left(Y_{i t}^{I}=Y_{i t}^{N} \forall t<T_{0}\right)$. This assumption, in our context, means that the policy change was not anticipated. We present evidence to support this assumption in Appendix B. The observed outcome is defined by $Y_{i t}=Y_{i t}^{N}+\alpha_{i t} D_{i t}$ where $\alpha_{i t}$ is the effect of the capital controls change on the variable of interest $\left(Y_{i t}^{I}-Y_{i t}^{N}\right)$ and $D_{i t}$ is the binary indicator denoting the event occurrence $\left(D_{i t}=1\right.$ for $t \geqslant T_{0}$ and $i=1$; and $D_{i t}=0$ otherwise). The aim is to estimate $\alpha_{i t}$ for all $t \geqslant T_{0}$ for Brazil $(i=1)$. The problem is that for all $t \geqslant T_{0}$ it is not possible to observe $Y_{1 t}^{N}$ but only $Y_{1 t}^{I}$.

Although there is no way of accurately predicting the countryspecific determinants of $Y_{i t}$, the structure of the emerging-market economies in our sample is fairly similar and the external shocks affecting them were fairly similar as well (except for mean zero iid shocks $\varepsilon_{i t}$ ). In this case, we suppose that $Y_{i t}^{N}$ can be given by the following factor model:

$Y_{i t}^{N}=\delta_{t}+\theta_{t} Z_{i}+\lambda_{t} \mu_{i}+\varepsilon_{i t}$

where $Z_{i}$ is a vector of observed covariates and $\mu_{i}$ is a vector of unknown factor loadings. Furthermore, we let $W=\left(\omega_{2}, \ldots, \omega_{I+1}\right)^{\prime}$ be a vector of weights allocated to the different country observations such that $\omega_{i} \geqslant 0$ for $i=2, \ldots, I+1$ and $\sum_{i=2}^{I+1} \omega_{i}=1$. The synthetic control is a weighted combination of the controls observations such that it replicates a treated unit as if the treatment had not occurred.

Suppose there is a set of optimal weights $\left(\hat{\omega}_{2}, \ldots, \hat{\omega}_{I+1}\right)$ that can accurately replicate Brazil's pre-treatment observations. Abadie et al. (2010, Appendix B) show that with a few reasonable assumptions, $Y_{1 t}^{N}=\sum_{i=2}^{l+1} \hat{\omega}_{i} Y_{i t}$. Furthermore they prove that this equality will hold for all $t$ given that the number of pre-treatment periods is large enough. ${ }^{16}$ Therefore we can use $\hat{\alpha}_{1 t}=Y_{1 t}-\sum_{j=2}^{I+1} \hat{\omega}_{j} Y_{j t}$ for

\footnotetext{
${ }^{14}$ Some of the countries may have long-standing controls/regulations of various types on the capital account. This is not likely to affect our results. Policy impact tends to be short-term, as they are very likely to be arbitrage away, and in any case these impacts, if they exist, should be consistent throughout the studied episodes. Thus, we already adjust for these consistent impacts with our estimation methodology (that only uses the pre-treatment sample separately for each episode.

${ }^{15}$ This description is a modified version of Abadie et al. (2010). To simplify comparison, we follow their notation where $I$ denotes intervention (capital account policy changed) and $N$ denotes non-intervention (policy not changed).

16 See proof in Abadie et al. (2010) Appendix B. Other recent papers that used the Abadie et al. (2010) methodology, albeit in very different contexts, are Nannicini and Billmeier (2011), Pinotti (2011), Abadie et al. (2012), Hinrichs (2012), Cavallo et al. (forthcoming), and duPont and Noy (2012).
} 
$t \geqslant T_{0}$ as an estimator for $\alpha_{1, t}$ provided we choose a set of weights, $W$.

We define $X_{1}=\left(Z_{1}^{\prime}, Y_{1}^{K_{1}}, \ldots, Y_{1}^{K_{M}}\right)$ a vector of pre-intervention characteristics of Brazil's capital flow regime, and similarly $X_{0}$ for the control countries. The set of weights $W$ is obtained by minimizing the distance between the observations of the treated unit $X_{1}$ and the observations for the group of control $X_{0} W$ during the pre-treatment period. We choose $W$ such that the following equation is minimized:

$\left\|X_{1}-X_{0} W\right\|_{V}=\sqrt{\left(X_{1}-X_{0} W\right)^{\prime} V\left(X_{1}-X_{0} W\right)}$

where $V$ is a $(k \times k)$ symmetric and positive semi-definite matrix ( $k$ is the number of explanatory variables). The choice of $V$ is important as it can greatly impact the mean square prediction error. We use the STATA synth routine to obtain $V$ such that the mean squared prediction error is minimized for the period prior to the policy change. ${ }^{17}$

The estimates of Eq. (1) are only used for constructing the counterfactual as accurately as possible. Thus, we are not interested in the actual coefficient estimates of these regressions as they have no economic significance or otherwise interpretable meaning. ${ }^{18}$

The usual statistical significance of our reported results, based on regression-based standard errors, is not relevant in this case since the uncertainty regarding the estimate of $\hat{\alpha}_{i t}$ does not come from uncertainty about the aggregate data. Uncertainty in comparative case studies with synthetic control is derived from uncertainty regarding the ability of the post-treatment synthetic control to replicate the counterfactual post-treatment in the treated observations.

Following Abadie et al. (2010), we use permutation tests to examine the statistical significance of our results: We separately assume that every other country in our control sample implements a similar (and imaginary) capital control in the same year. We then produce counterfactual synthetic control for each "placebo control." These synthetic counterfactuals for the placebos are then used to calculate the impact of the placebo capital controls $\left(\hat{\alpha}_{i t}^{p}\right)$ in every year following its (non)-occurrence with the following formula:

$\hat{\alpha}_{i t}^{P}=Y_{i t}^{I}-\hat{Y}_{i t}^{N}=Y_{i t}^{I}-\left[\hat{\delta}+\sum_{j=2}^{J} \hat{\omega}_{j} Y_{j t}^{N}\right]$ for $t \geqslant T_{0}$ and $j \neq P$

Essentially, we investigate whether the $\hat{\alpha}_{1 t}$ we estimated for Brazil are statistically different from the placebo $\hat{\alpha}_{i t}^{P}$ for $i>1$. We present the placebo results only for episodes in which we find any visible impact of the change in the capital control regime.

\section{Results}

\subsection{Results for capital inflows and exchange rate}

We graph the actual evolution of capital inflows (as recorded in the EPFR data we use) and the synthetic control that assumes no change in policy. These figures therefore show the counter-factual evolution of capital flows had the changes in capital account policy not occurred. We summarize these results chronologically for each change in Brazil's capital account policies 2008-2011:

\footnotetext{
17 The STATA program is described at: http://www.mit.edu/ jhainm/ synthpage.html.

18 Results for the synthetic weights we obtain are available in Appendix A. When we examine the data for the control group of countries (those whose weights are different from zero) and Brazil, we generally find similar trends in the pre-events data, suggesting that the shocks Brazil were experiencing were common and there is no evidence to support the argument that the conditions leading to the placing of controls were unique to Brazil. These figures are available upon request.
}

The first act - March 2008 (taxing fixed income only) - is reported in Fig. 1. We observe a decline in flows in the run-up to the placing of controls, but that funds start flowing in again (net) about 2 weeks before the episode; this budding inflow may be the impetus for the placing of controls (Fig. 1A). The placing of controls did not appear to have a large influence. There was a small and temporary slowdown in the inflow episode that resulted from the controls. While we observe a continuation of the inflow for the counter-factual scenario, Brazil experienced a similar dramatic rise, but with about a month's delay. We are not confident that this delay, however, is a result of the imposed controls since it is also present in inflows to other Latin American destinations that did not put any controls in place. ${ }^{19} \mathrm{~A}$ similarly very brief deviation from the counter-factual can be also observed for the exchange rate (Fig. 1B). Within 3-4 weeks, we can no longer identify any residual impact of the imposition of controls on the exchange rate.

In Fig. 2, we report on the second act - October 2008 (removing the fixed-income tax during the Lehman aftermath). Inflows were decreasing rapidly throughout the pre-crisis period starting in July, 2008 (Fig. 2A). We observe evidence of a slowdown in the capital outflows as a result of this removal of controls in October. The counter-factual Brazil (without the relaxation of controls) would have experienced a continuing capital flight. Latin America funds (La$\mathrm{tAm}$ ), also seem to continue declining during this period, though at a slowing rate, which suggests that the removal of the IOF did indeed have the intended effect. In Fig. 2B we present the placebo test for this episode; the evidence only suggests an impact that is statistically observable as non-coincidental (i.e., the gap between the Brazilian flows and the counter-factual is bigger than for the majority of the placebos). The evidence regarding the exchange rate is not as robust (Fig. 2C), but there still does appear to be a longer-term impact on the exchange rate than the one we observed in the first episode. Even that, however, appeared to be a transitory phenomenon.

Third act - October 2009 (taxing both equity and bonds at 2\%): The policy aim was to reduce inflows, and that did not seem to work (Fig. 3A). Brazil continued experiencing inflows as did the rest of LatAm (if anything, the inflows for Brazil are rising faster than for other Latin American funds) ${ }^{20}$ We find no evidence that the imposition of controls had any impact of the exchange rate (Fig. 3B).

Fourth act - October 2010 (tax going up to $4 \%$ on fixed income): In Fig. 4A, we again observe an ineffective control as increase in the IOF does not interrupt the continuing inflow episode (as it did for other LatAm countries; but with a bigger impact for Brazil). In both acts Three and Four of 2009 and 2010, the post-control inflow boom episodes seem to be large and unique (since the actual is significantly larger than the synthetic and unique to Brazil relative to LatAm funds). The controls did not manage to stem the volume of these inflows, though they may have produced other desirable outcomes (more on that below). In the next change in policy, presented in Fig. 4B, the IOF was further increased to $6 \%$ only 2 weeks after the previous increase (October 2010). Again, the further tightening of controls appears ineffective in stemming inflows. We do not show the corresponding figures for the exchange rate, but the results are similarly non-significant. ${ }^{21}$

Fifth act - January 2011 (reducing taxes on equities). In Fig. 5A, we observe a short-run surge in equity investment that is unique to the Brazil funds and may be attributable to the reduction in the tax on equities. But this surge reverses quickly; and post-rever-

\footnotetext{
19 These results for the Latin American funds are not presented in the figures but are available upon request.

${ }^{20}$ If anything, inflows increased further after the tightening of controls. Since the controls were imposed as a capital inflow surge was beginning, it is difficult to speculate whether the controls were somehow a signal that encouraged further flows (a possibility that is suggested in the survey data that Forbes et al., 2012 present).

${ }^{21}$ Results are available upon request from the corresponding author.
} 


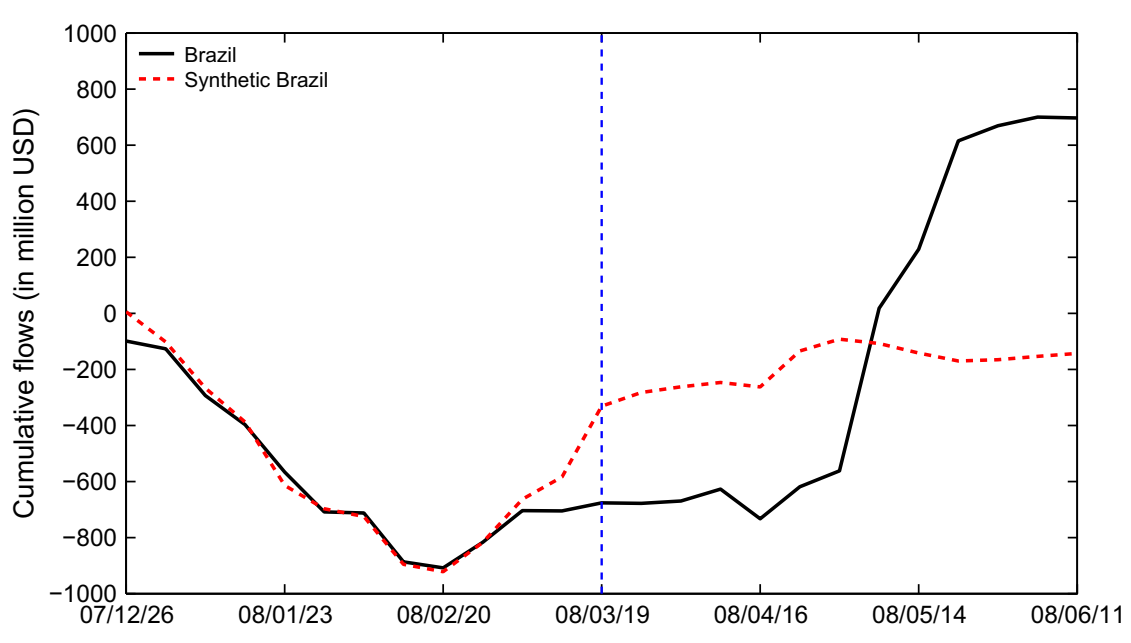

Fig. 1A. 2008-3-12 Taxing fixed income investment - CAPITAL FLOWS.

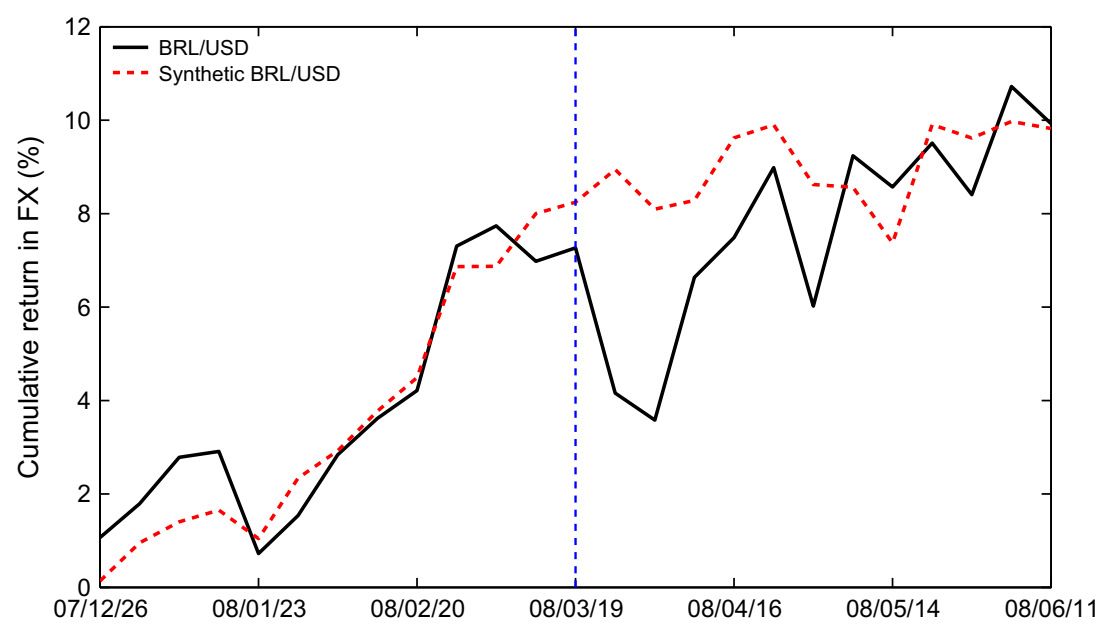

Fig. 1B. 2008-3-12 Taxing fixed income investment - EXCHANGE RATE.

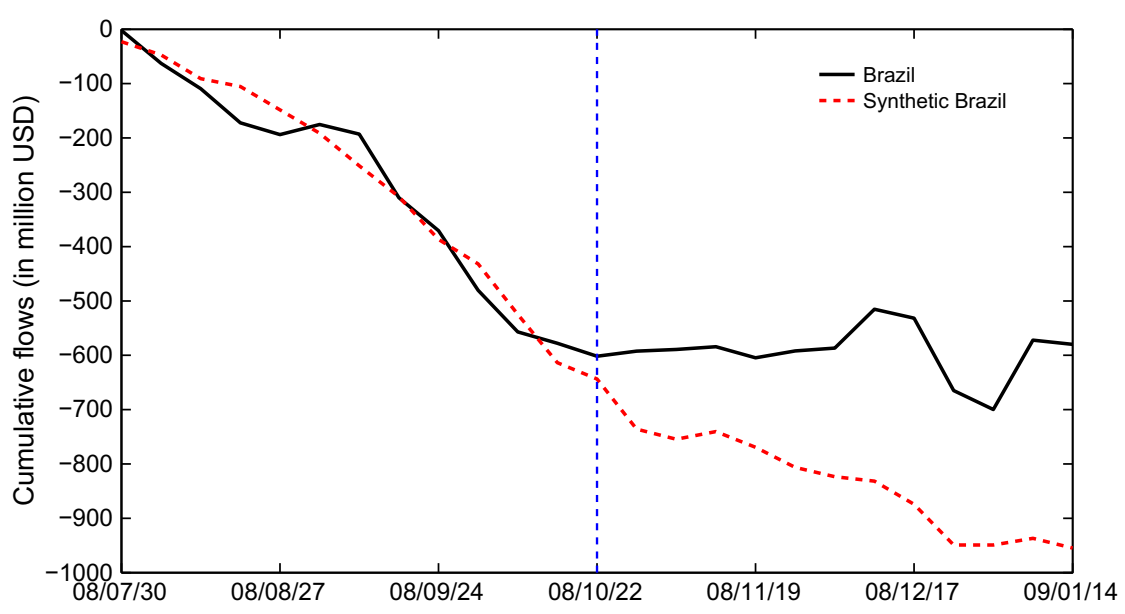

Fig. 2A. 2008-10-23 Cutting fixed income tax - CAPITAL FLOWS.

sal decline is equivalent to a general decline in funds going to LatAm in the first 3 months of 2011. This conclusion is borne out when examining the placebos graphed in Fig. 5B; again, we surmise that a relaxation of controls did appear to have a very short term, but both statistically and economically meaningful impact on capital flows. In the longer-term (3 months in our framework) there does not seem to be any significant impact. The same findings, a brief deviation from the counter-factual and a reversion back to the pre-change equilibrium can also be found in the estimations of the exchange rate (Fig. 5C). 


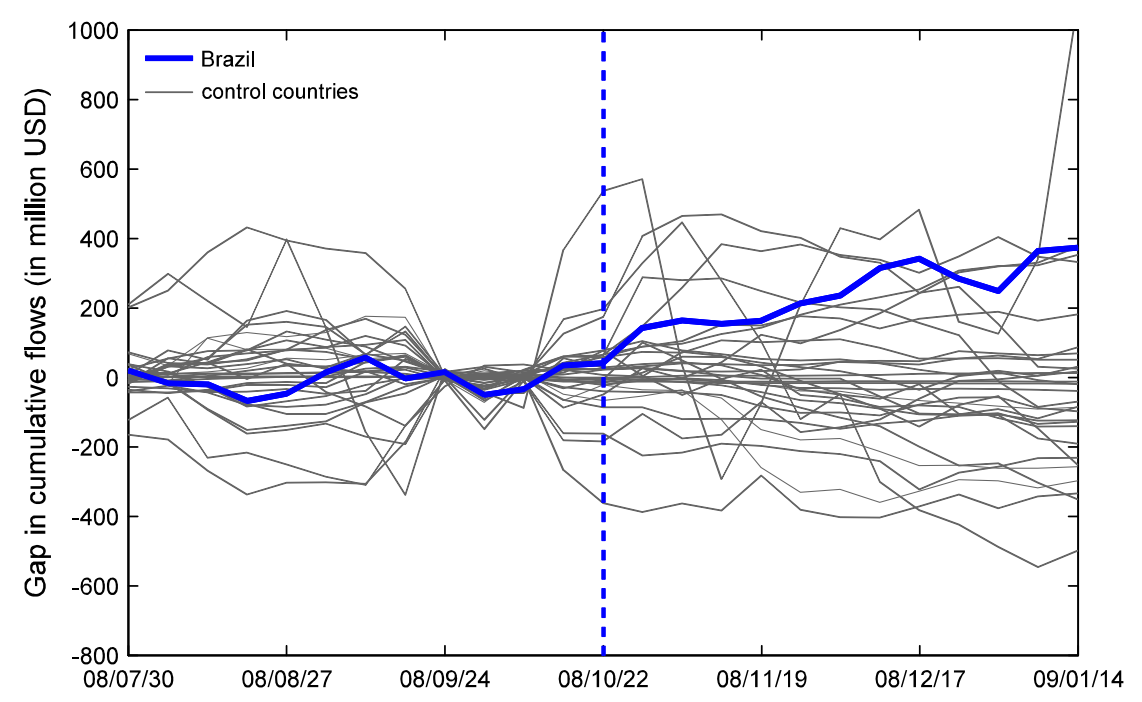

Fig. 2B. 2008-10-23 Cutting fixed income tax - Placebos.

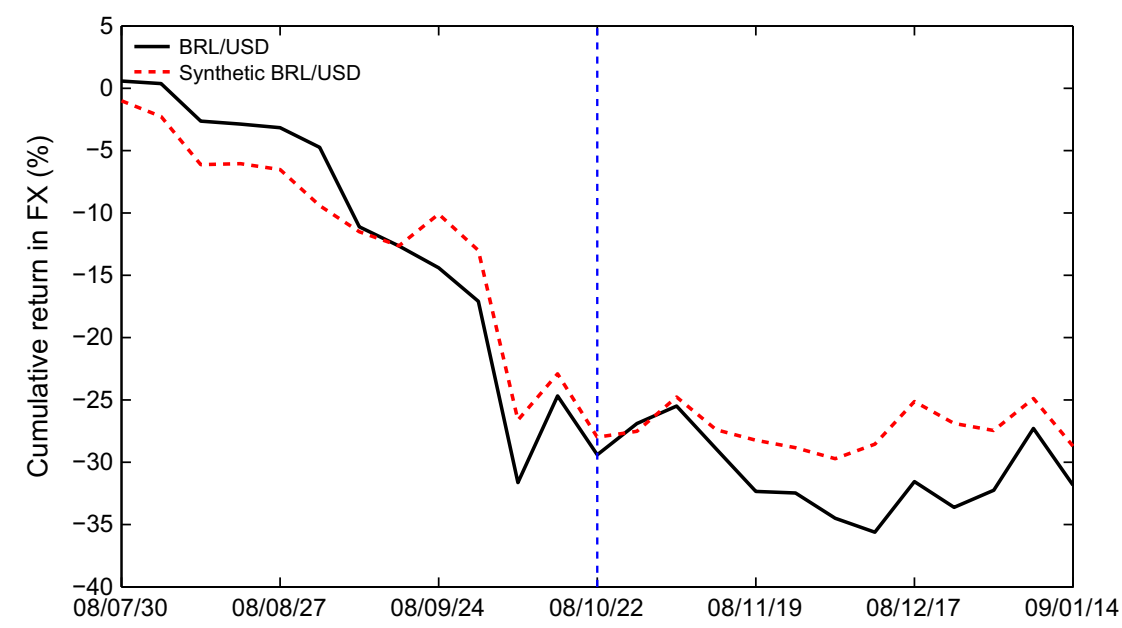

Fig. 2C. 2008-10-23 Cutting fixed income tax - EXCHANGE RATE.

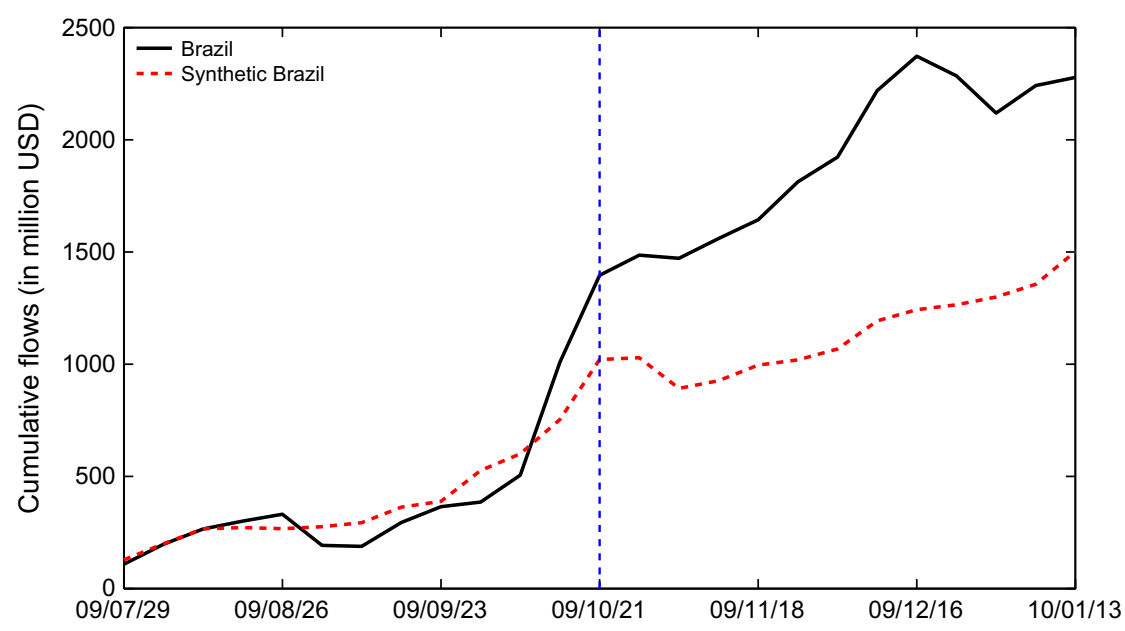

Fig. 3A. 2009-10-20 Taxing stock and bond investment at 2\% - CAPITAL FLOWS.

4.2. Summary of empirical findings - capital controls as a signal

To summarize, after controlling for the counter-factual (Brazil with no capital account policy change) for each event in which Brazil modified its capital controls during the first 3 years of the
Global Financial Crisis, we find no evidence that any tightening of controls were effective in reducing the magnitudes of capital inflows into the country. We do observe some modest success in preventing further declines in inflows when the capital controls are relaxed as was done in the immediate aftermath of the Lehman 


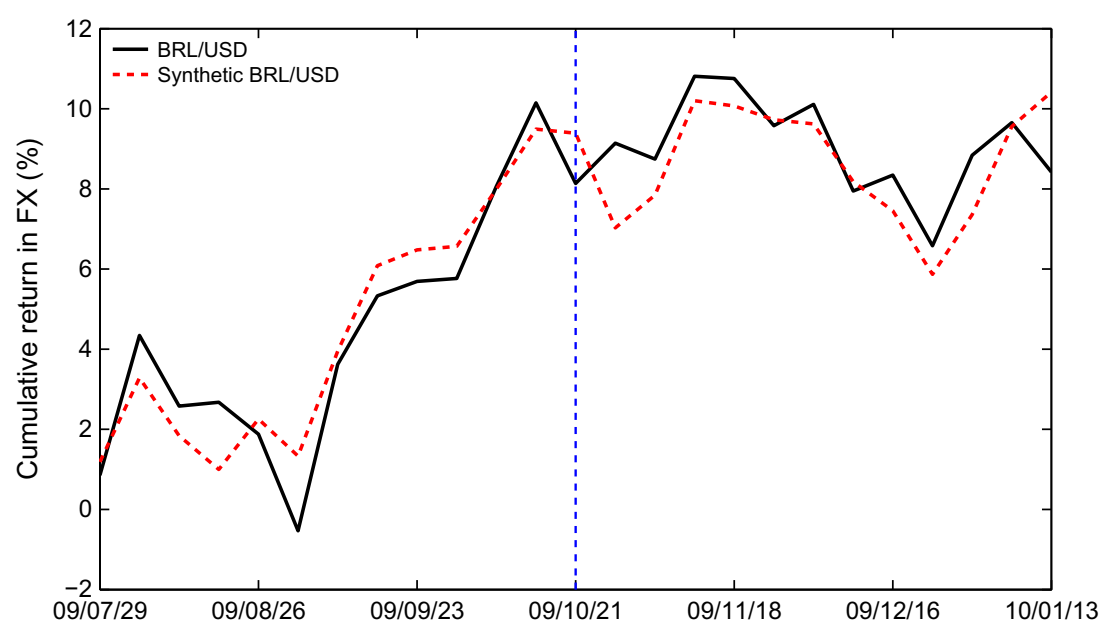

Fig. 3B. 2009-10-20 Taxing stock and bond investment at 2\% - EXCHANGE RATE.

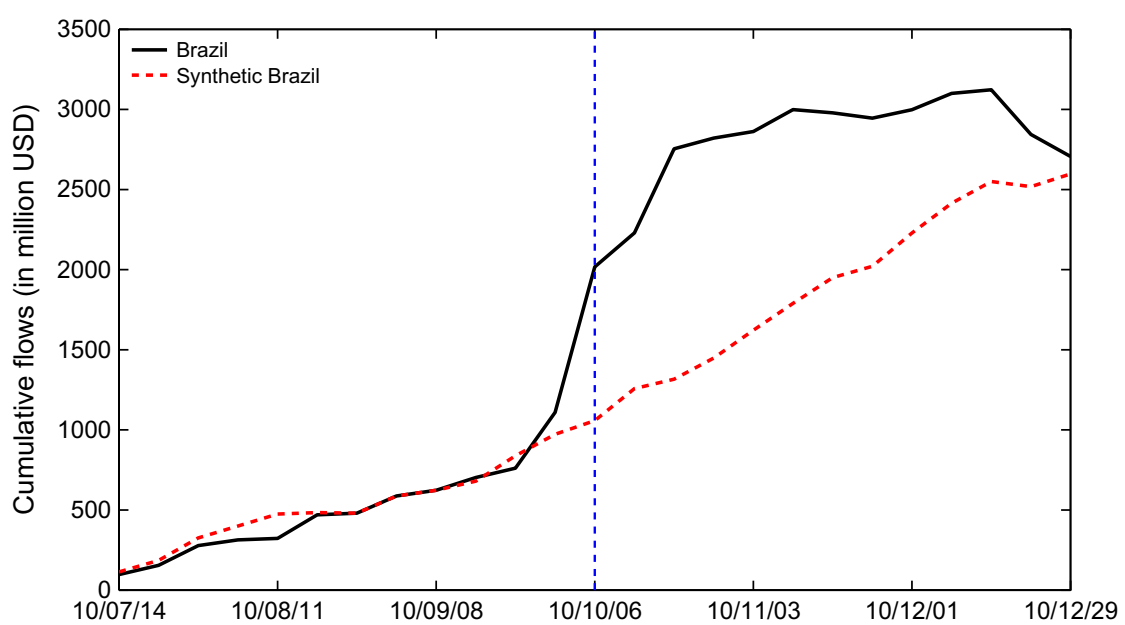

Fig. 4A. 2010-10-4 Increasing taxes 2-4\% - CAPITAL FLOWS.

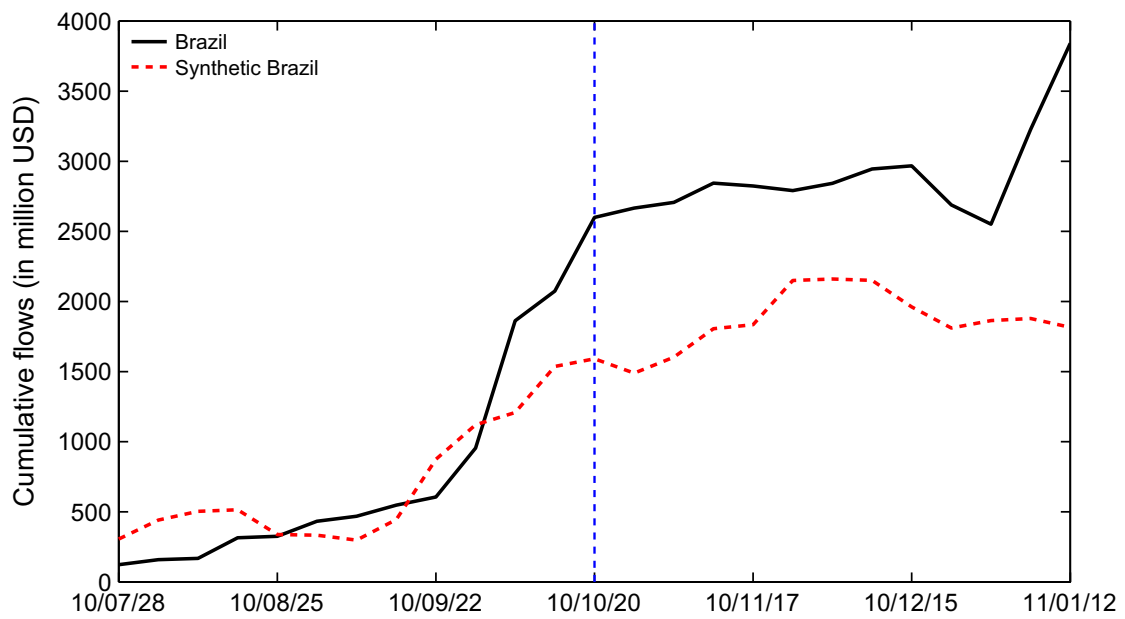

Fig. 4B. 2010-10-18 Increasing taxes 4-6\% - EXCHANGE RATE (and increasing taxes on margins from 0.38\% to 6\%). Note: The sample period overlap with the last synthetic analysis. The large gap several weeks before the capital control may be attributed to previous control.

bankruptcy in 2008 and the associated massive credit contraction worldwide. A similar modest success can be attributed to the decision by the Brazilian government to reduce taxes in January 2011.
Both of these decisions to relax controls were instituted during a capital outflow episode, and these successes were more evident in preventing further decreases in capital inflows than in any sustained 


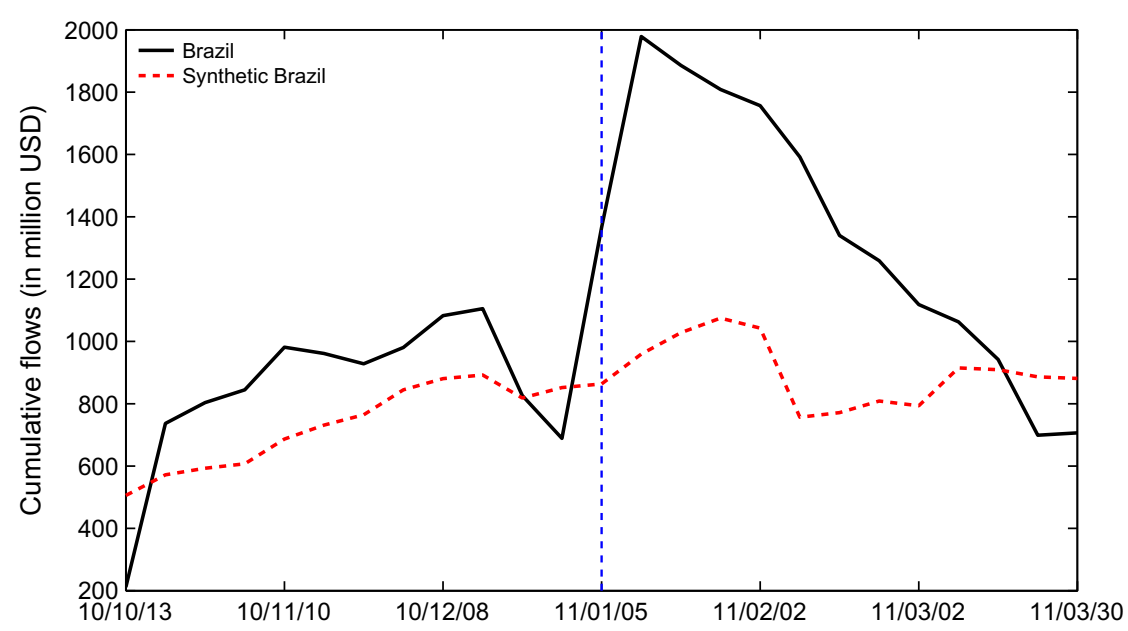

Fig. 5A. 2011-1-3 Reducing taxes from $6 \%$ to $2 \%$ - CAPITAL FLOWS.

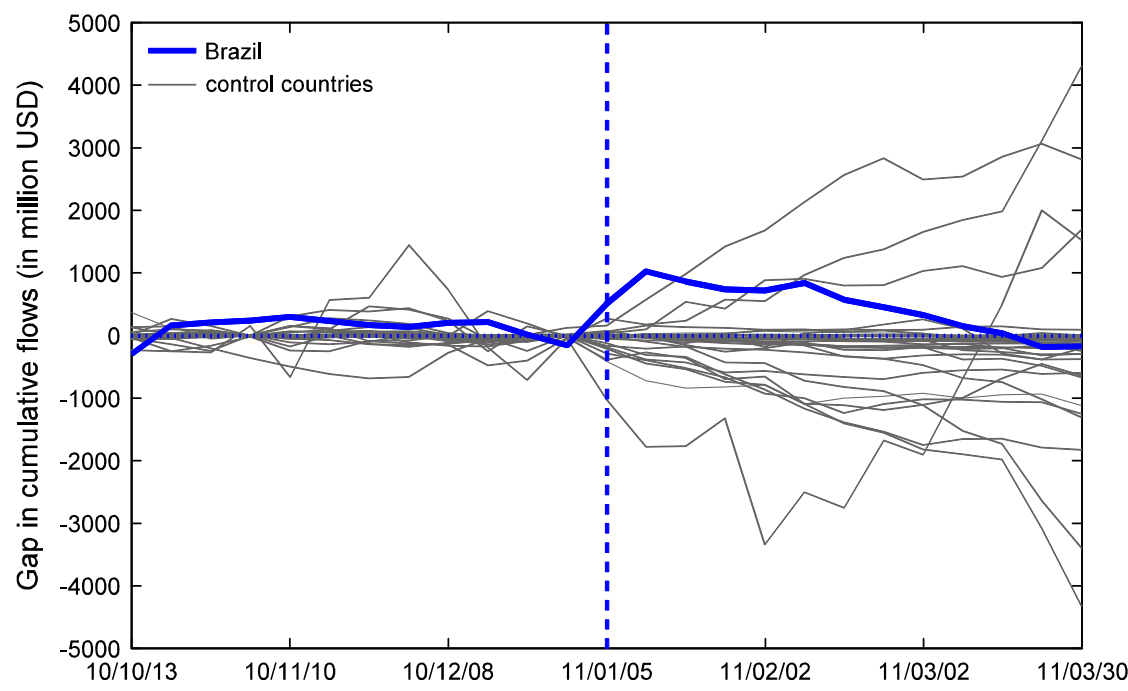

Fig. 5B. 2011-1-3 Reducing taxes from $6 \%$ to $2 \%$ - Placebos.

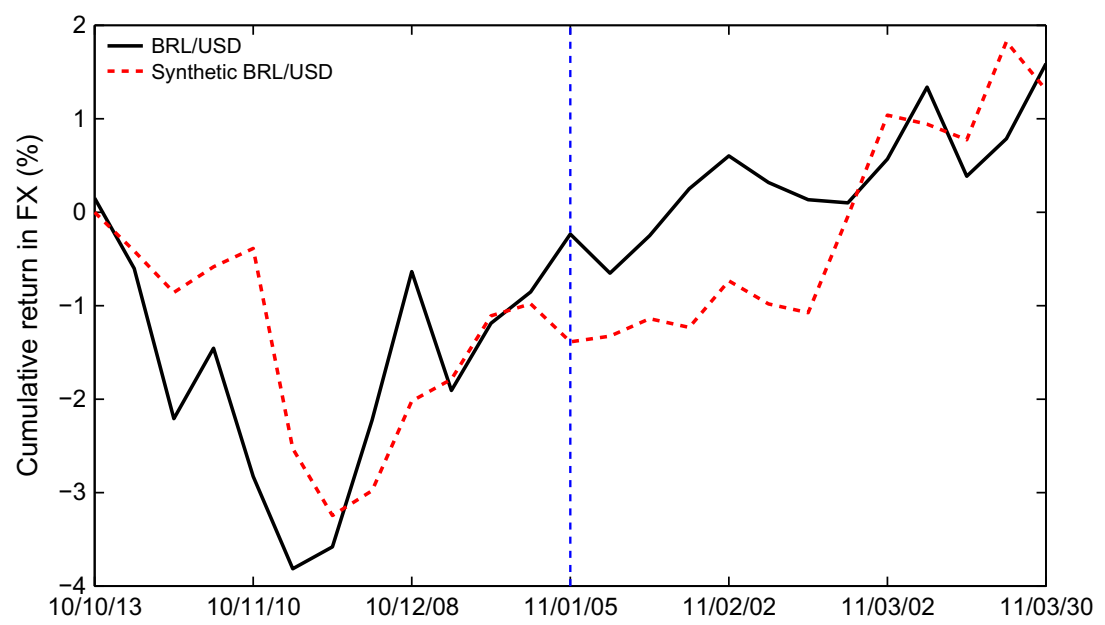

Fig. 5C. 2011-1-3 Reducing taxes from 6\% to $2 \%$ - EXCHANGE RATE.

impact on the exchange rate. These results complement survey responses described in Forbes et al. (2012). In these surveys of investment managers, the overall conclusion Forbes et al. (2012) reach is that investment managers' reactions to fairly limited capital account policy changes in a large open economy like Brazil is very muted and remarkably heterogeneous. Given these heterogeneous sentiments it may not be a surprise that we find so little impact that can be accounted for by the tightening of the capital account regime. 
Another possibility is that the controls did have a portfolio balancing impact even if indeed they had no impact on funds' size, since the households and corporations and other entities that invest in funds did not react to the imposition of controls. It may still be the case that fund managers did divert money from Brazil to other countries within the funds they manage. Given the data limitations, we cannot test this possibility.

Why did we find an asymmetric impact? Why is there a significant impact when controls were removed? The interviews that were conducted by Forbes et al. (2012) suggest that many money managers were more interested in the signal content of the capital account policy change rather than in the direct impact of the changes on their tax liability and therefore on their bottom lines. Brazil, throughout this period, was controlled by the left-of-center Workers' Party headed by Lula. ${ }^{22}$ Our hypothesis is that price-based, mild capital controls' only perceptible effect are to be found in the content of the signal they broadcast regarding the government's larger intentions and sensibilities. In Lula's case, the government was widely perceived as ambivalent to markets, and especially to the international capital markets. Thus, an imposition of (fairly mild) controls was not perceived as 'news' and thus had no impact. A willingness to remove controls, however, as happened in October 2008 in the middle of the global post-Lehman financial panic and then again in January 2011, just after the transition from Lula to Dilma Rousseff's administration were both apparently perceived as noteworthy indications that the government was not as hostile to the international financial markets as many expected it to be. The removal of controls was thus effective since the presumption was that the government had some antipathy to financial markets and foreign investors. This of course, suggests that the same policy may have a different impact within a political environment in which the government is perceived differently.

\subsection{Brazil and the BRIC}

The weights we obtained in constructing our synthetic controls (see Appendix D) have no real economic meaning, but do describe the conditional correlation between flows to Brazil and flows to the other countries in our sample. Interestingly, the other BRIC countries (Russia, India and China) seem to figure quite prominently as controls (with the occasional addition of Mexico, Australia, Indonesia, Taiwan). This is interesting in and of itself, since Russia and Brazil are large commodity exporters, and India and China's sectoral composition of trade is quite different. Investment managers of the funds included in the dataset seem to treat the BRIC as similar substitutes and capital inflows to them appear to be motivated similarly. Capital flows in Brazil are correlated much more closely with the other members of the BRIC club rather than with regional neighbors like Argentina or Chile, and other large agricultural exporters like Colombia or Thailand.

Forbes et al. (2012) focus on the externalities created by the imposition of capital controls, and how the imposition/relaxation of controls in one country (Brazil) may lead to reallocation of portfolio shares that may have an impact on other countries' capital flows. We therefore estimate the impact of Brazil's five episodes of change in its capital account regime on the other BRIC club members, Russia, India and China. In most cases, we do not observe any statistically visible deviation between the synthetic and the actual flows - so that Brazil's policy changes had no apparent impact. In a few instances, however, there do seem to be notable deviations; in particular we observe that for China in the first episode (an inflow surge), Russia in the second episode (outflow), China

${ }^{22}$ Luiz Inácio Lula da Silva. Replaced on 1/1/2011 by Dilma Rousseff from the same left-of-center political party. again in the third episode (again an inflow surge), and India and China in the fifth episode (outflow). But these deviations fit with our notion that Brazil is attempting to 'lean-against-the-wind' while the other BRIC are facing the same head- or tail-winds themselves. Unlike Forbes et al. (2012), we are hesitant to conclude that this is a sign of an externality; it is equally plausible that these changes in controls were implemented when all the BRIC were experiencing very similar capital inflow surges or capital flights/ retrenchments.

\section{Caveats and future research}

In an IMF April 2011 meeting discussing the IMF's guidelines for supporting the use of capital controls, the Brazilian Finance Minister Guido Mantega voiced his opposition. He declared: "We oppose any guidelines, frameworks or 'codes of conduct' that attempt to constrain, directly or indirectly, policy responses of countries facing surges in volatile capital inflows. Governments must have flexibility and discretion to adopt policies that they consider appropriate." (Reddy, 2011). The Brazilian government, as well as other representatives from emerging markets, found the IMF's limited support of capital controls as a prudential policy tool as too limited and constraining, and argued for a broader mandate to use this set of tools.

In what can be perceived as a limited confirmation of this concern, IMF researchers recently concluded, in the case of several Eastern European countries that were experiencing heavy inflows, that the conditions prevailing in these cases did not justify the imposition of controls; and advocated more conventional monetary and fiscal adjustments (Chowdhury and Keller, 2012). If one uses the broad framework that the IMF suggests, however, on most accounts Brazil in 2008-2010 appeared to have been a good candidate for the imposition of controls.

It is remarkable, therefore, that we fail to find much impact of these controls given their intended rationale in limiting the volume of capital flowing into a potentially over-heated economy, and the vocal support these policies have garnered from many corners of the policy world. These findings suggest that mild price-based controls appear effective only if they are surprising and provide a signal regarding the government's larger policy trajectory. Clearly, using controls as a signal is both costly, inefficient, and can only be used infrequently. A sceptical reader may, of course, suggest that our results may not be robust and our failure to uncover the direct impacts of controls (bar their signalling impact) is a failure of our methodology. While this is a possibility, a spate of other recent work has also failed to find much evidence for a significant impact of 'mild' controls, or is generally sceptical of any claims of the efficacy of these control-such as these that were implemented in the Brazilian case (e.g., Calvo, 2010; Warnock, 2011; Edwards, 2012; Fratzscher, 2012; Straetmans et al., 2013; Chari, 2013).

An additional possibility is that the Brazilian case is not representative and any conclusions will not be applicable elsewhere. This is a general criticism of any case-study, and applicability of a case is never assured; again, we argue that given the prevalence of similar conclusions in this recent spate of cross-country research projects, we believe the Brazilian case is most likely representative of the larger truth: 'mild' capital controls are largely ineffective unless they provide a signal regarding the general trajectory of government economic policy ('draconian' controls are, by definition, effective).

The reasons for instituting these policies, of course, may be political and electoral in nature, rather than being truly guided by a desire to obtain any of the impacts we described. It may be indeed that policy makers fully understand the inability of these 
controls to have any substantial impact, but nevertheless resort to adopting them. We leave that possibility for future work.

\section{Appendix A. Estimation results for synthetic analysis in Figs. 1-5}

The following set of tables in Appendix A compares the pretreatment characteristics of the treated (actual) Brazil with that of the synthetic Brazil. The synthetic Brazil is constructed as the combination of countries chosen from the sample that most closely resembled Brazil in term of capital flows before Brazil introduced the capital account policy change specified in the title of each table (and the date it was implemented). See Appendix $\mathrm{C}$ for a full list of countries and their synthetic weights used to construct the synthetic observation. The reported statistics are the mean values of the actual and synthetic explanatory variables for the pre-treatment periods, which are 12 weeks prior to the week of policy change. Root Mean Squared Prediction Error (RMSPE) is calculated as the root mean of the weighted squared distance between the treated and synthetic capital flows for the pre-treatment periods (see Tables A1-A5).

\section{Appendix B. Were Brazilian capital controls anticipated?}

In this appendix, we examine an empirical association between the announcements of capital control measures and any potential market and public anticipation of these announcements. We aim to verify that the timing of announcements used in the main study is indeed a surprise (regardless of its news content and economic significance) and therefore cannot be forecasted quantitatively by capital market indicators and surveys. While our main findings in Sections 2-4 are based on five major announcements from 2008 to 2011 as we were constrained by the weekly fund flows data, this appendix reports several tests over the whole post GFC sample period 2008-2012, and also provides a description of all announcements of control measures, as briefly outlined in the following.

The IOF that was initially imposed on foreign investors' bond investment was announced on 12 March 2008. On 23 October 2008, the government announced the elimination of the financial transaction tax on foreign investors, which at the time stood at $1.5 \%$ on foreign exchange transactions for capital inflows and $0.38 \%$ on foreign currency loans. By mid October 2009, the Reais again appreciated markedly and the IOF was re-imposed on 20 October 2009. In September 2010, the Reais appreciation increased markedly again, and on October 4,2010 , the government announced an immediate increase of IOF tax on bond from $2 \%$ to $4 \%$. Then, on 18 October 2010 , the government announced additional IOF tax increase from 4\% to 6\%. By early December 2010, the market still speculated that the IOF tax might be raised further from $6 \%$ on the bond investment, but remained $2 \%$ on the equity investment (since speculation in the stock market did not seem to pose much threat). On 3 January 2011, the

Table A1

Estimation results: 2008-3-12 taxing fixed income investment.

\begin{tabular}{lrr}
\hline Variables & \multicolumn{1}{c}{ Treated } & Synthetic \\
\hline Cumulative flow on the week end at 2008-2-6 & -712.080 & -724.852 \\
Cumulative flow on the week end at 2008-2-27 & -816.750 & -817.039 \\
Mutual fund return & 6.086 & 1.972 \\
log(TNA) & 9.464 & 8.863 \\
Weekly return on stock market index & 1.904 & -0.473 \\
Weekly return on bond market index & 1.898 & 1.812 \\
Weekly return on foreign exchange rate & 5.704 & 3.991 \\
RMSPE (Root Mean Squared Prediction Error) & 53.084 & \\
\hline
\end{tabular}

Table A2

Estimation results: 2008-10-23 cutting fixed income tax.

\begin{tabular}{lrr}
\hline Variables & Treated & Synthetic \\
\hline Cumulative flow on the week end at 2008-9-24 & -370.620 & -386.686 \\
Cumulative flow on the week end at 2008-10-8 & -557.050 & -524.667 \\
Mutual fund return & -54.740 & -42.002 \\
log(TNA) & 9.225 & 8.689 \\
Weekly return on stock market index & -36.250 & -35.266 \\
Weekly return on bond market index & 2.084 & 0.219 \\
Weekly return on foreign exchange rate & -21.446 & -9.756 \\
RMSPE (Root Mean Squared Prediction Error) & 36.664 & \\
\hline
\end{tabular}

Table A3

Estimation results: $2009-10-20$ taxing stock and bond investment at $2 \%$.

\begin{tabular}{lrr}
\hline Variables & Treated & Synthetic \\
\hline Cumulative flow on the week end at 2009-8-5 & 197.340 & 199.387 \\
Cumulative flow on the week end at 2009-8-12 & 265.390 & 266.513 \\
Mutual fund return & 26.661 & 25.029 \\
log(TNA) & 9.609 & 8.558 \\
Weekly return on stock market index & 18.949 & 23.702 \\
Weekly return on bond market index & 1.358 & 2.574 \\
Weekly return on foreign exchange rate & 8.262 & 5.382 \\
RMSPE (Root Mean Squared Prediction Error) & 101.242 & \\
\hline
\end{tabular}

Table A.4A

Estimation results: $2010-10-4$ increasing taxes $2-4 \%$.

\begin{tabular}{lrr}
\hline Variables & Treated & Synthetic \\
\hline Cumulative flow on the week end at 2010-8-25 & 480.330 & 480.233 \\
Cumulative flow on the week end at 2010-9-1 & 587.620 & 587.774 \\
Mutual fund return & 10.150 & 10.112 \\
log(TNA) & 9.921 & 9.869 \\
Weekly return on stock market index & 7.818 & 7.779 \\
Weekly return on bond market index & 1.632 & 1.293 \\
Weekly return on foreign exchange rate & 3.482 & 3.825 \\
RMSPE (Root Mean Squared Prediction Error) & 70.546 & \\
\hline
\end{tabular}

Table A.4B

Estimation results: $2010-10-18$ increasing taxes $4-6 \%$.

\begin{tabular}{lrr}
\hline Variables & \multicolumn{1}{c}{ Treated } & Synthetic \\
\hline Cumulative flow on the week end at 2010-9-25 & 606.060 & 874.442 \\
Cumulative flow on the week end at 2010-10-13 & 2074.290 & 1536.694 \\
Mutual fund return & 14.347 & 11.746 \\
log(TNA) & 9.964 & 10.615 \\
Weekly return on stock market index & 9.170 & 10.649 \\
Weekly return on bond market index & 1.536 & 0.365 \\
Weekly return on foreign exchange rate & 5.048 & 1.718 \\
RMSPE (Root Mean Squared Prediction Error) & 307.223 & \\
\hline
\end{tabular}

Table A5

Estimation results: $2011-1-3$ reducing taxes from $6 \%$ to $2 \%$.

\begin{tabular}{lrr}
\hline Variables & Treated & Synthetic \\
\hline Cumulative flow on the week end at 2010-11-3 & 844.590 & 607.302 \\
Cumulative flow on the week end at 2010-11-29 & 688.920 & 851.904 \\
Mutual fund return & -0.064 & 3.382 \\
log(TNA) & 10.115 & 9.082 \\
Weekly return on stock market index & -1.809 & 5.026 \\
Weekly return on bond market index & 1.352 & 1.873 \\
Weekly return on foreign exchange rate & -0.657 & 2.985 \\
RMSPE (Root Mean Squared Prediction Error) & 206.968 & \\
\hline
\end{tabular}

government announced a reduction on the IOF tax on private equity funds, venture capital funds, and depository receipts from $6 \%$ to $2 \%$. By mid 2011, as the appreciation of Reais regained its momentum, the government announced a tax on trading of 

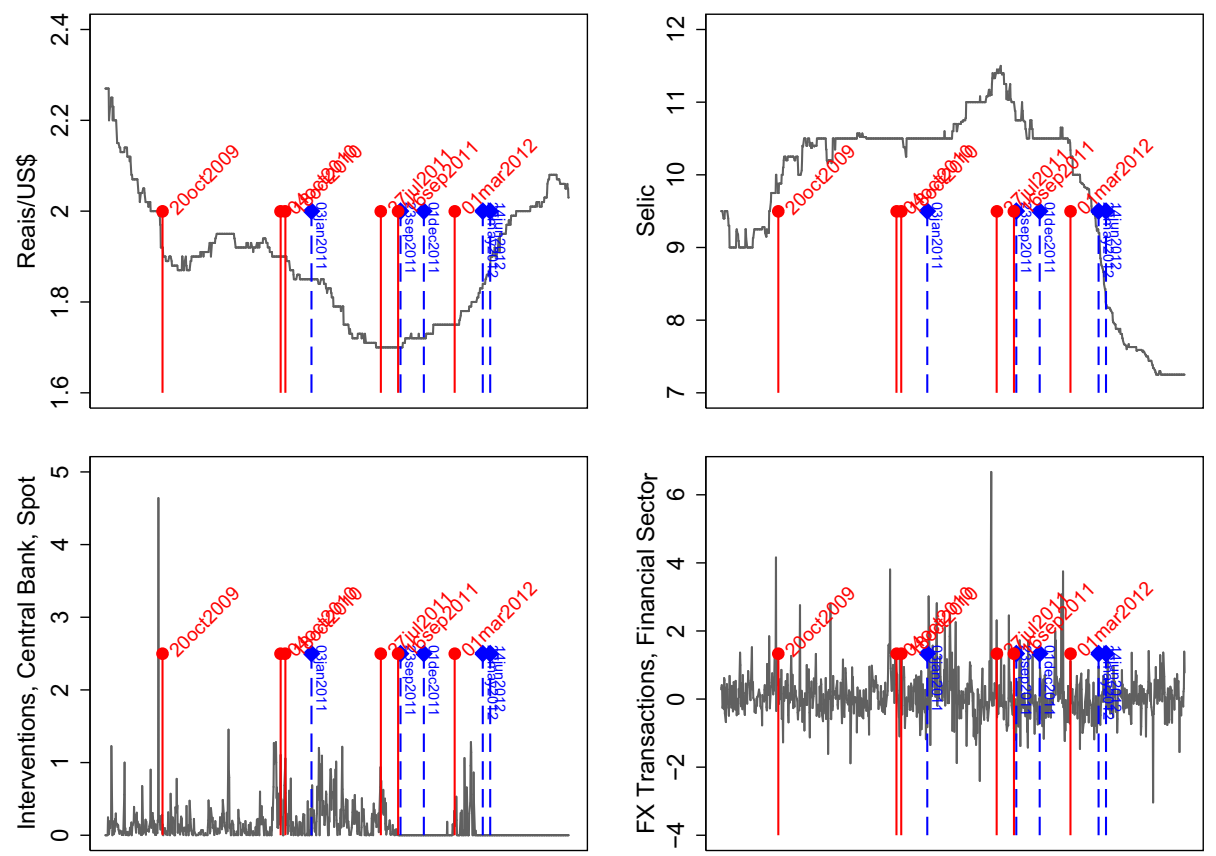

Fig. B1. Announcements of capital control measures and capital market indicators. This figure plots the daily series of business surveys of expectation on Reais/US\$ and expectation on Selic rates, as well as the spot foreign exchange invention by Banco Central do Brasil (in billion of US\$) and the net (purchases minus sales) foreign exchange transactions by financial sectors in Brazil (in billion of US\$). The drop lines in solid identify announcement dates of capital control tightening (increase); the drop lines in dash identify announcement dates of capital control loosening (decrease).

currency derivatives on 27 July 2011, and then outlined its detailed plan on 16 September 2011 for a $1 \%$ tax on currency derivatives, but on 23 September 2011 decided to delay the tax until the end of December. As the threat of Euro crisis mounted over the global markets, the government announced on 1 December 2011 that the IOF tax on equity investment and corporate bond investment was immediately scrapped. By early March 2012, however, the Reais' appreciation renewed

Table B1

Anticipation of the Announcements of capital control measures.

\begin{tabular}{|c|c|c|c|c|c|c|c|c|}
\hline \multirow{3}{*}{$\begin{array}{l}\text { Capital control } \\
\text { Surveyed var. }\end{array}$} & \multicolumn{4}{|l|}{ Probit } & \multirow{2}{*}{\multicolumn{2}{|c|}{$\begin{array}{l}\text { Bivariate Probit } \\
(3) \\
\text { Increase }\end{array}$}} & \multirow{2}{*}{\multicolumn{2}{|c|}{ Decrease }} \\
\hline & \multicolumn{2}{|c|}{$\begin{array}{l}(1) \\
\text { Increase }\end{array}$} & \multicolumn{2}{|c|}{$\begin{array}{l}(2) \\
\text { Decrease }\end{array}$} & & & & \\
\hline & Coeff. & (SE) & Coeff. & (SE) & Coeff. & (SE) & Coeff. & (SE) \\
\hline Reais/US\$ $\$_{t}$ & 3.90 & $(3.17)$ & 31.01 & $(13.18)^{* *}$ & & & 27.01 & (38.70) \\
\hline Selic $_{t}$ & -2.70 & (2.19) & -1.94 & $(1.32)$ & -6.87 & (5.33) & -0.82 & $(6.70)$ \\
\hline Intervention $_{t}$ & 0.53 & $(0.26)^{* *}$ & -0.63 & $(1.17)$ & -1.72 & (3.86) & & \\
\hline FX Gross Flows $t_{t}$ & 0.20 & $(0.16)$ & -0.19 & $(0.30)$ & -0.20 & $(0.45)$ & -0.21 & $(0.53)$ \\
\hline Reais/US\$ $\$_{t-1}$ & & & & & -1.66 & (9.19) & -7.57 & $(4.78)$ \\
\hline Reais/US\$ $\$_{t-2}$ & & & & & -0.55 & (6.16) & -9.00 & (5.69) \\
\hline Reais/US\$ $\$_{t-3}$ & & & & & 1.94 & (5.03) & -0.92 & (4.77) \\
\hline Selic $_{t-1}$ & & & & & 0.86 & $(0.91)$ & & \\
\hline Selic $_{t-2}$ & & & & & 2.02 & $(3.72)$ & & \\
\hline Selic $_{t-3}$ & & & & & -12.26 & $(14.48)$ & & \\
\hline Intervention $_{t-1}$ & & & & & -0.08 & $(0.49)$ & -0.38 & $(0.50)$ \\
\hline Intervention $_{t-2}$ & & & & & -0.34 & $(0.52)$ & -0.24 & $(0.46)$ \\
\hline Intervention $_{t-3}$ & & & & & -0.26 & $(0.68)$ & -0.76 & $(0.71)$ \\
\hline FX Gross Flows $s_{t-1}$ & & & & & & & -19.32 & $(58.91)$ \\
\hline FX Gross Flows $t_{t-2}$ & & & & & & & 70.46 & (69.06) \\
\hline FX Gross Flows $t_{t-3}$ & & & & & & & 5.84 & $(47.87)$ \\
\hline Constant term & -2.70 & $(0.17)^{* * *}$ & -2.58 & $(0.18)^{* * * *}$ & -2.64 & $(0.42)^{* * *}$ & -3.15 & $(0.59)^{* * * *}$ \\
\hline No. of days & 979 & & 979 & & 391 & & & \\
\hline Pseudo $R^{2}$ & 0.0825 & & 0.0560 & & Prob. $>c$ & 937 & & \\
\hline
\end{tabular}

This table reports an empirical association between the announcements of capital control measures and any potential market and public anticipation. The estimation is based on 11 (out of 13) announcement dates from 2008 to 2012 as discussed in the Appendix. The daily series, collected from DataStream, are available from 4 May 2009 , and include business surveys of expectation on Reais/US\$ and expectation on Selic rates, as well as the spot foreign exchange invention by Banco Central do Brasil (in billion of US\$) and the net (purchases minus sales) foreign exchange transactions by financial sectors in Brazil (in billion of US\$). Based on the Dickey-Fuller tests, the Reais/US\$ and the Selic series are non-stationary; these two are first differenced. Standard errors are in parentheses.

* Statistical significant at $10 \%$ level.

** Statistical significant at $5 \%$ level.

*** Statistical significant at $1 \%$ level. 
and government announced on 1 March 2012 that the 6\% IOF tax on foreign loans with maturities up to 2 years, now extended to those with maturities up to 3 years. On 23 May 2012, the government decided to drop the IOF tax on the purchase of derivatives instruments for exporters, and on 14 June 2012, the government announced a reduction on financial transaction tax on foreign loans to domestic firms.

To study whether the announcements were anticipated by the public, we look at the daily movements of several capital market indicators, including business surveys of expectation on Reais/US\$ and expectation on Selic rates, as well as the spot foreign exchange invention by Banco Central do Brasil (in billion of US\$) and the net (purchases minus sales) foreign exchange transactions by financial sectors in Brazil (in billion of US\$). We collected the data from DataStream, which make available these daily series from 4 May 2009; we are thus able to study 11 out of the 13 dates abovementioned. Appendix Fig. B1 plots the four series, marked with the 11 announcement dates. As shown, it appears the announcements were not forecasted by these market indicators. There are some possibilities nonetheless: on one occasion for an increase in the capital control measure announced on 20 October 2009, when it was preceded by a significant intervention in spot foreign exchange markets by the central bank on 8 October 2009; and on several occasions when there were seemingly correlations between net foreign exchange transactions by the financial sector and the decreases of capital control measures.

We formally test the relationship between the announcement dates and the market indicators by using probabilistic regres- sions. Based on the Dickey-Fuller tests, we find that the Reais/ US\$ and the Selic series are non-stationary; these two are then first differenced. As a first pass, we estimate a Probit model of announcement dates on the four variables contemporaneously. Columns (1) and (2) of Appendix Table B1 report the estimation results for the six increases and the five decreases of the control announcement dates, respectively. We find the central bank's intervention is positively associated with the increase announcements, while the Reais' depreciation is positively associated with the decrease announcements. However, the explanatory power of both Probit regressions, as measured by the Pseudo $R^{2}$, is very low. Next, we proceed with a Bivariate Probit regression, whereby the increase announcement is a function of Selic rate, central bank intervention, and net (purchases minus sales) foreign exchange transactions by the financial sector; and the decrease announcement is a function of Reais/US\$, Selic rate, and net foreign exchange transactions by the financial sector, and both functions are estimated simultaneously. To account for any lagged effects of these market indicators, we also include their lags up to 3 days preceding the announcement dates. The estimation results in column (3) of the table suggest that any association between the announcement dates and the market indicators is rather weak and not statistically significant. Neither the increase nor the decrease announcements signify any statistical relationship with the capital market indicators, all of which are publicly available. Therefore, we conclude that these policy changes were not anticipated in any rigorous (actionable) way by market participants for the episodes of capital control measures that we are focusing on.

\section{Appendix C. The correlation between EPFR and BOP data}

This table reports the correlation coefficients between EPFR mutual fund flows (EPFR) and three official measures of cross-border capital flows reported by IMF Balance of Payments Statistics (BOP), namely the net portfolio investment (PI), the net equity component of the portfolio investment (EPI) and the foreign direct investment (FDI). The sample period is from 2007 Q4 to 2011 Q1.

\begin{tabular}{|c|c|c|c|c|c|c|c|}
\hline Country & $\rho_{P I, E P F R}$ & $\rho_{E P I, E P F R}$ & $\rho_{\text {FDI,EPFR }}$ & Country & $\rho_{P I, E P F R}$ & $\rho_{\text {EPI,EPFR }}$ & $\rho_{F D I, E P F R}$ \\
\hline Australia & 0.174 & -0.053 & 0.174 & Malaysia & $0.585^{*}$ & 0.454 & -0.317 \\
\hline Austria & 0.076 & -0.211 & 0.428 & Mexico & -0.263 & & 0.194 \\
\hline Belgium & 0.401 & 0.150 & 0.367 & Netherlands & 0.304 & 0.173 & -0.155 \\
\hline Brazil & 0.245 & 0.478 & 0.140 & New Zealand & 0.566 & 0.169 & -0.350 \\
\hline Canada & 0.196 & 0.167 & 0.210 & Norway & -0.217 & 0.192 & 0.104 \\
\hline Chile & -0.211 & -0.121 & 0.162 & Philippines & $0.543^{*}$ & 0.509 & -0.174 \\
\hline China & -0.086 & -0.032 & 0.249 & Poland & 0.231 & 0.065 & -0.632 \\
\hline Colombia & 0.104 & & $-0.900^{* * *}$ & Portugal & -0.157 & -0.179 & $0.874^{*}$ \\
\hline Czech Republic & -0.121 & 0.031 & $0.675^{* *}$ & Russia & $0.563^{*}$ & $0.601^{*}$ & 0.032 \\
\hline Denmark & -0.376 & -0.355 & -0.537 & Singapore & -0.263 & & 0.139 \\
\hline Egypt & -0.379 & & & South Africa & -0.055 & 0.058 & 0.050 \\
\hline Finland & -0.743 & -0.564 & -0.479 & South Korea & 0.173 & -0.167 & -0.181 \\
\hline France & 0.023 & -0.059 & 0.044 & Spain & -0.018 & 0.036 & -0.261 \\
\hline Germany & -0.399 & -0.033 & 0.139 & Sweden & -0.078 & 0.457 & -0.260 \\
\hline Greece & 0.169 & 0.040 & -0.120 & Switzerland & -0.272 & 0.171 & -0.353 \\
\hline Hong Kong & -0.086 & 0.086 & -0.115 & Taiwan & -0.005 & & 0.299 \\
\hline India & $\mathbf{0 . 7 3 1}^{* *}$ & 0.652 & 0.006 & Thailand & 0.022 & 0.076 & 0.283 \\
\hline Indonesia & 0.163 & $0.838^{* * *}$ & -0.044 & Turkey & 0.081 & & -0.149 \\
\hline Israel & 0.037 & 0.080 & $0.552^{*}$ & United Kingdom & -0.284 & -0.287 & 0.009 \\
\hline Italy & -0.058 & -0.505 & 0.502 & United States & 0.000 & -0.004 & 0.338 \\
\hline Japan & 0.242 & 0.460 & 0.239 & Vietnam & 0.228 & & -0.172 \\
\hline
\end{tabular}

Data Source: IMF Balance of Payments Statistics (BOP), Central Bank of the Republic of China (Taiwan) and Central Bank of Egypt.

Statistical significant at $10 \%$ level.

** Statistical significant at 5\% level.

*** Statistical significant at $1 \%$ level. 


\section{Appendix D. Country weights for synthetic capital flows to Brazil}

For each episode of capital control, we study 12 weeks (approximately one quarter) before and after the week of its implementation. A country is included as a possible component of the control group if, for the given 25-week sample period, it did not introduce any capital controls and it had no missing observations for the selected control variables, namely mutual fund return, TNA, weekly return on stock market index, weekly return on bond market index and weekly return on foreign exchange rate.

2008-3-12: Taxing fixed income investment.

\begin{tabular}{llllll}
\hline Country & Weight & Country & Weight & Country & Weight \\
\hline Australia & $\mathbf{0 . 1 1 9}$ & Indonesia & 0.000 & South Africa & 0.000 \\
Austria & 0.000 & Israel & 0.000 & South Korea & 0.000 \\
Belgium & 0.000 & Italy & 0.000 & Spain & 0.000 \\
Canada & 0.000 & Japan & 0.000 & Sweden & 0.000 \\
Chile & $\mathbf{0 . 0 5 1}$ & Malaysia & 0.000 & Switzerland & 0.000 \\
China & 0.000 & Mexico & 0.000 & Taiwan & $\mathbf{0 . 4 9 6}$ \\
Czech Republic & 0.000 & Netherlands & 0.000 & Thailand & 0.000 \\
Egypt & 0.000 & Norway & 0.000 & Turkey & 0.000 \\
France & 0.000 & Philippines & 0.000 & United Kingdom & $\mathbf{0 . 3 2 6}$ \\
Hong Kong & 0.000 & Russia & 0.000 & United States & 0.009 \\
India & 0.000 & Singapore & 0.000 & Vietnam & 0.000 \\
\hline
\end{tabular}

2008-10-23: Cutting fixed income tax.

\begin{tabular}{llllll}
\hline Country & Weight & Country & Weight & Country & Weight \\
\hline Australia & 0.000 & Indonesia & 0.000 & South Africa & 0.000 \\
Austria & 0.000 & Israel & 0.000 & South Korea & 0.000 \\
Belgium & 0.000 & Italy & 0.000 & Spain & 0.000 \\
Canada & 0.000 & Japan & 0.000 & Sweden & 0.000 \\
Chile & 0.000 & Malaysia & 0.000 & Switzerland & 0.000 \\
China & 0.000 & Mexico & $\mathbf{0 . 1 4 0}$ & Taiwan & $\mathbf{0 . 2 9 4}$ \\
Czech Republic & 0.000 & Netherlands & 0.000 & Thailand & 0.000 \\
Egypt & 0.000 & New Zealand & 0.000 & Turkey & 0.000 \\
France & 0.000 & Norway & 0.000 & United Kingdom \\
Germany & 0.000 & Philippines & 0.000 & United States & 0.000 \\
Greece & 0.000 & Portugal & 0.000 & Vietnam & 0.000 \\
Hong Kong & 0.000 & Russia & $\mathbf{0 . 2 4 4}$ & & \\
India & $\mathbf{0 . 3 2 2}$ & Singapore & 0.000 & & \\
\hline
\end{tabular}

2009-10-20: Taxing stock and bond investment at $2 \%$.

\begin{tabular}{llllll}
\hline Country & Weight & Country & Weight & Country & Weight \\
\hline Australia & $\mathbf{0 . 0 9 7}$ & Greece & 0.000 & Russia & $\mathbf{0 . 4 5 6}$ \\
Austria & 0.000 & Hong Kong & 0.000 & Singapore & 0.000 \\
Belgium & 0.000 & India & $\mathbf{0 . 3 2 0}$ & South Africa & 0.000 \\
Canada & 0.000 & Indonesia & $\mathbf{0 . 1 2 6}$ & Spain & 0.000 \\
Chile & 0.000 & Israel & 0.000 & Sweden & 0.000 \\
China & 0.000 & Italy & 0.000 & Switzerland & 0.000 \\
Colombia & 0.000 & Japan & 0.000 & Taiwan & 0.000 \\
Czech Republic & 0.000 & Malaysia & 0.000 & Thailand & 0.000 \\
Denmark & 0.000 & Mexico & 0.000 & Turkey & 0.000 \\
Egypt & 0.000 & Netherlands & 0.000 & United Kingdom \\
France & 0.000 & New Zealand & 0.000 & United States & 0.000 \\
Germany & 0.000 & Norway & 0.000 & Vietnam & 0.000 \\
\hline
\end{tabular}


2010-10-4: Increasing taxes from $2 \%$ to $4 \%$.

\begin{tabular}{lllll}
\hline Country & Weight & Country & Weight & Country \\
\hline Australia & 0.000 & Germany & $\mathbf{0 . 3 1 2}$ & Philippines \\
Austria & 0.000 & Greece & 0.000 & Poland \\
Belgium & 0.000 & Hong Kong & $\mathbf{0 . 1 2 0}$ & Singapore \\
Canada & 0.000 & India & $\mathbf{0 . 3 0 6}$ & South Africa \\
Chile & 0.000 & Israel & 0.000 & Spain \\
China & $\mathbf{0 . 2 0 2}$ & Italy & 0.000 & Sweden \\
Colombia & 0.000 & Japan & 0.000 & Switzerland \\
Czech Republic & 0.000 & Malaysia & 0.000 & United Kingdom \\
Denmark & 0.000 & Mexico & 0.000 & United States \\
Egypt & 0.000 & Netherlands & 0.000 & Vietnam \\
Finland & 0.000 & New Zealand & 0.000 & 0.000 \\
France & $\mathbf{0 . 0 3 2}$ & Norway & 0.000 & 0.000 \\
\hline
\end{tabular}

2010-10-18: Increasing taxes from $4 \%$ to $6 \%$ and increasing taxes on margins from $0.38 \%$ to $6 \%$.

\begin{tabular}{|c|c|c|c|c|c|}
\hline Country & Weight & Country & Weight & Country & Weight \\
\hline Australia & 0.000 & Germany & 0.000 & Philippines & 0.000 \\
\hline Austria & 0.000 & Greece & 0.000 & Poland & 0.000 \\
\hline Belgium & 0.000 & Hong Kong & 0.000 & Singapore & 0.000 \\
\hline Canada & 0.000 & India & 0.097 & South Africa & 0.000 \\
\hline Chile & 0.000 & Israel & 0.000 & Spain & 0.000 \\
\hline China & 0.903 & Italy & 0.000 & Sweden & 0.000 \\
\hline Colombia & 0.000 & Japan & 0.000 & Switzerland & 0.000 \\
\hline Czech Republic & 0.000 & Malaysia & 0.000 & United Kingdom & 0.000 \\
\hline Denmark & 0.000 & Mexico & 0.000 & United States & 0.000 \\
\hline Egypt & 0.000 & Netherlands & 0.000 & Vietnam & 0.000 \\
\hline Finland & 0.000 & New Zealand & 0.000 & & \\
\hline France & 0.000 & Norway & 0.000 & & \\
\hline
\end{tabular}

2011-1-3: Reducing taxes from $6 \%$ to $2 \%$.

\begin{tabular}{lllll}
\hline Country & Weight & Country & Weight & Country \\
\hline Australia & $\mathbf{0 . 9 5 2}$ & Germany & $\mathbf{0 . 0 4 8}$ & Philippines \\
Austria & 0.000 & Greece & 0.000 & Poland \\
Belgium & 0.000 & Hong Kong & 0.000 & Portugal \\
Canada & 0.000 & India & 0.000 & Russia \\
Chile & 0.000 & Israel & 0.000 & Singapore \\
China & 0.000 & Italy & 0.000 & South Africa \\
Colombia & 0.000 & Japan & 0.000 & Spain \\
Czech Republic & 0.000 & Malaysia & 0.000 & Sweden \\
Denmark & 0.000 & Mexico & 0.000 & Switzerland \\
Egypt & 0.000 & Netherlands & 0.000 & United Kingdom \\
Finland & 0.000 & New Zealand & 0.000 & 0.000 \\
France & 0.000 & Norway & 0.000 & United States \\
\hline
\end{tabular}

\section{References}

Abadie, A., Diamond, A., Hainmueller, J., 2010. Synthetic control methods for comparative case studies: estimating the effect of California's tobacco control program. Journal of the American Statistical Association 105 (490), 493-505.

Abadie, A., Diamond, A., Hainmueller, J., 2012. Comparative Politics and the Synthetic Control Method. MIT Political Science Department Research Paper No. 2011-25.

Abadie, A., Gardeazabal, J., 2003. The economic costs of conflict: a case study of the Basque country. American Economic Review 93 (1), 113-132.

Baba C., Kokenyne A., 2011. Effectiveness of Capital Controls in Selected Emerging Markets in the 2000s. IMF Working Paper. 11/281.

Binici, M., Hutchison, M., Schindler, M., 2010. Controlling capital? Legal restrictions and the asset composition of international financial flows. Journal of International Money and Finance 29 (4), 666-684.
Calvo, G., 2010. Controls on Cyclical Capital Inflows - Some Skeptical Notes. <http:// vox.lacea.org/?q=node/20>.

Carvalho, B, Garcia, M. 2008. Ineffective controls on capital inflows in sophisticated financial markets: Brazil in the Nineties. In: Edwards, S., Garcia, M. (Eds.), Financial Market Volatility and Performance in Emerging Markets. University of Chicago Press.

Cavallo, E., Galiani, S., Noy, I., Pantano, J., forthcoming. Catastrophic natural disasters and economic growth. Review of Economic and Statistics.

Chari, A., 2013. Book review of Olivier Jeanne, Arvind Subramanian, John Williamson, who needs to open the capital account? Journal of International Economics 90 (1), 232-233.

Chinn, M., Ito, H., 2006. What matters for financial development? Capital controls, institutions, and interactions. Journal of Development Economics 81, 163192.

Chowdhury, I., Keller, L., 2012. Managing Large-scale Capital Inflows: The Case of the Czech Republic, Poland and Romania. IMF Working Paper 12/138. 
DuPont, W., Noy, I., 2012. What Happened to Kobe? A Reassessment of the Impact of the 1995 Earthquake in Japan, Working Papers 201204. University of Hawaii at Manoa, Department of Economics.

Edwards, S., 1999. How effective are capital controls? Journal of Economic Perspectives 13 (4), 65-84.

Edwards, S., 2012. The Federal Reserve, Emerging Markets, and Capital Controls: A High Frequency Empirical Investigation. NBER Working Paper No. 18557.

Financial Times, 2010, "Why Capital Controls are Not All Bad", in Opinion, by Ilene Grabel and Ha-Joon Chang, October 25

Forbes, K., Fratzscher, M., Kostka, T., Straub, R., 2012. Bubble thy Neighbor: Portfolio Effects and Externalities from Capital Controls. NBER Working Paper No. 18052

Fratzscher, M., 2012. Capital flows, push versus pull factors and the global financial crisis. Journal of International Economics 88 (2), 341-356.

Glick, R., Guo, X., Hutchison, M., 2006. Currency crises, capital account liberalization, and selection bias. Review of Economics and Statistics 88 (4) 698-714.

Goldfajn, I., Minella, A., 2005. Capital Flows and Controls in Brazil: What have We Learned? NBER Working Paper.

Hinrichs, P., 2012. The effects of affirmative action bans on college enrollment, educational attainment, and the demographic composition of universities. Review of Economics and Statistics 94 (3), 712-722.

IMF, 2012. The Liberalization and Management of Capital Flows: An Institutiona View. International Monetary Fund Position Paper.

Jeanne, O., 2012a. Capital flow management. American Economic Review 102 (3), $203-206$.

Jeanne, O., 2012b. Capital Account Policies and the Real Exchange Rate. NBER Working Paper No. 18404

Joyce, J., Noy, I., 2008. The IMF and the liberalization of capital flows. Review of International Economics 16 (3), 413-430.
Klein, M., 2012. Capital Controls: Gates Versus Walls. NBER Working Paper No. 18526

Magud, N.E., Reinhart, C.M., Rogoff, K.S., 2011. Capital Controls: Myth and Reality A Portfolio Balance Approach. NBER No. 16805.

Miniane, J., 2004. A new set of measures on capital account restrictions. IMF Staff Papers 51, 276-308.

Nannicini, T., Billmeier, A., 2011. Economies in transition: how important is trade openness for growth? Oxford Bulletin of Economics and Statistics 73, 287-314. OECD, 2011. OECD Economic Surveys: Brazil. Paris.

Ostry, J., Ghosh, A., Chamon, M., Qureshi, M., 2011. Capital controls: when and why? IMF Economic Review 59 (3).

Ostry, J., Ghosh, A., Chamon, M., Qureshi, M., 2012. Tools for managing financialstability risks from capital inflows. Journal of International Economics 88, 407421.

Pinotti, P., 2011. The Economic Consequences of Organized Crime: Evidence from Southern Italy. Manuscript.

Reddy, S., 2011. Emerging nations reject capital plan: IMF delays program to help countries manage short-term inflows; as Geithner blames China, others blame the Fed. Wall Street Journal, 4/18/2011.

Schindler, M., 2009. Measuring financial integration: a new data set. IMF Staff Papers 56 (1), 222-238.

Straetmans, S., Versteeg, R., Wolff, C., 2013. Are capital controls in the foreign exchange market effective. Journal of International Money and Finance, June 2013, (35), 36-53.

The Economist, 2013, "Phoney Currency Wars", in The Global Economy, February 16.

Warnock F., 2011. Doubts about Capital Controls. Council on Foreign Relations: Comment. 